\title{
Two cases of granuloma mimicking local recurrence after pulmonary segmentectomy
}

\author{
Mikio Okazaki ${ }^{1 *} \mathbb{D}$, Yoshifumi Sano ${ }^{1}$, Yu Mori ${ }^{1}$, Nobuhiko Sakao ${ }^{1}$, Syungo Yukumi ${ }^{2}$, Hisayuki Shigematsu ${ }^{1}$ and
} Hironori Izutani ${ }^{1}$

\begin{abstract}
Background: Fluorodeoxyglucose (FDG)-positron emission tomography (PET)/CT is the most sensitive non-invasive imaging method for the detection of tumor metastasis and recurrence, but sometimes reveals false-positive results. Herein, we report two cases of false-positive results on PET/CT scans along with elevated serum carcinoembryonic antigen (CEA) levels, mimicking local recurrence after pulmonary segmentectomy.

Case presentation: Case 1; A 75-year-old woman underwent thoracoscopic left basal segmentectomy for primary lung cancer. Follow-up at 6 months after the surgery revealed serum CEA level elevation and chest CT showed a nodule measuring $25 \times 22 \mathrm{~mm}$ in the residual left lower lobe. PET/CT revealed FDG uptake in the nodule diagnosed as local recurrence of lung cancer, and the patient underwent partial resection of the nodule. Microscopic examination of the resected specimen revealed granuloma caused by polyglycolic acid (PGA) sheet. Case 2; A 58-year-old man underwent VATS right S1 segmentectomy for lung metastasis from rectal carcinoma. Serum CEA levels gradually increased after surgery, and PET/CT revealed FDG uptake in the stump diagnosed as local recurrence of the lung metastasis. The patient underwent completion lobectomy 6 months after the segmentectomy, and the pathology of the resected specimen revealed an inflammatory granuloma caused by PGA suture.

Conclusions: Although suture and stapler granulomas have been reported, granuloma caused by PGA sheets has never been reported. Postoperative recurrence of lung cancer should be diagnosed with not only PET/CT scans and serum tumor markers but also pathological findings, to avoid unnecessary treatment such as chemotherapy, radiation, and difficult reoperation.
\end{abstract}

Keywords: Lung cancer, Granuloma, Segmentectomy, Polyglycolic acid sheet

\section{Background}

When physicians suspect postoperative recurrence of lung cancer owing to elevated serum tumor marker levels and computed tomography (CT) findings, fluorodeoxyglucose (FDG)-positron emission tomography (PET)/CT is performed. FDG-PET/CT is the most sensitive non-invasive imaging method for the detection of tumor metastasis and recurrence [1]. However, PET/CT sometimes reveals false-positive results owing to infectious diseases, sarcoidosis, radiation pneumonitis, and

\footnotetext{
* Correspondence: mikio.ok@io.ocn.ne.jp

1 Department of Cardiovascular and Thoracic Surgery, Ehime University

Medical School, Toon City, Japan

Full list of author information is available at the end of the article
}

post-operative surgical conditions [2]. Herein, we report two cases of false-positive results on PET/CT scans along with elevated serum carcinoembryonic antigen (CEA) levels, mimicking local recurrence after pulmonary segmentectomy.

\section{Case presentation \\ Case 1}

A 75-year-old woman underwent video-assisted thoracic surgery (VATS) left basal segmentectomy for primary lung cancer. The intersegmental plane was cut via electrocautery, and the surface was covered with a polyglycolic acid (PGA) sheet and fibrin glue. Pathology of the resected specimen revealed a mixed adenocarcinoma 
(pathological stage IA). Follow-up at 6 months after the surgery revealed serum CEA level elevation to $10.0 \mathrm{ng} /$ $\mathrm{mL}$. Chest CT showed a nodule measuring $25 \times 22 \mathrm{~mm}$ in the residual left lower lobe (Fig. 1a), and PET/CT revealed FDG uptake in the nodule (maximum standardized uptake value [SUVmax]: 5.3) (Fig. 1b). The pathological diagnosis of the nodule with bronchoscopic or CT guided biopsy was difficult because of the location. However, these clinical findings suggested highly suspected local recurrence of lung cancer, and the patient underwent partial resection of the nodule through thoracotomy. The total operative time was $244 \mathrm{~min}$, and total blood loss was $350 \mathrm{~mL}$. Pathology of the resected specimen revealed an inflammatory granuloma. There were no findings of malignancy. Microscopic examination revealed hyperplasia of collagen fibers (Fig. 1c) with granulomatous nodules and foreign body giant cells (Fig. 1d). There was no evidence of infection such as mycobacteria and fungus. On immunohistochemical examination, the granuloma and fibrous scars did not show CEA-positive cells (Fig. 1e), although CEA-positive cells were partially visible in the alveolar epithelium, and the serum CEA level decreased to $4.8 \mathrm{ng} / \mathrm{mL}, 7$ days after the surgery.

\section{Case 2}

A 58-year-old man underwent VATS right S1 segmentectomy for lung metastasis from rectal carcinoma. The intersegmental plane was cut via electrocautery, and the stump was suture-closed with 4-0 PGA sutures. Serum CEA levels gradually increased after surgery, and PET/ CT revealed FDG uptake in the stump (SUVmax: 6.8, Fig. 2b) diagnosed as local recurrence of the lung metastasis. The patient underwent completion lobectomy through thoracotomy 6 months after the segmentectomy. The pulmonary artery tightly adhered to the surrounding tissue, and exposure of the pulmonary artery was difficult. Therefore, the total operative time was 344 min, and total blood loss was $4100 \mathrm{~mL}$ owing to pulmonary artery injury. Microscopy of the resected specimen revealed no malignant findings (Fig. 2c). Granulomatous nodules with foreign-body giant cells were observed in part of the fibrous scars (Fig. 2d). There was no evidence of infection such as mycobacteria and fungus. Immunohistochemistry revealed CEA positivity, although CEA-positive cells were not observed in the granuloma and fibrous scar (Fig. 2e).

\section{Discussion}

Pulmonary granuloma is caused by inflammation; infection of bacteria, fungi, and human herpesvirus-8 [3]; and foreign bodies. Sutures and staplers also cause granuloma after lung resection $[4,5]$, in particular, stapler granulomas due to foreign body reaction $[4,6]$. Although Munteanu et al. first reported suture granuloma by PGA suture [7], pulmonary granulomas caused by a PGA sheet have never been reported. PGA sheets are synthetic bioabsorbable meshes made with polyglycolic
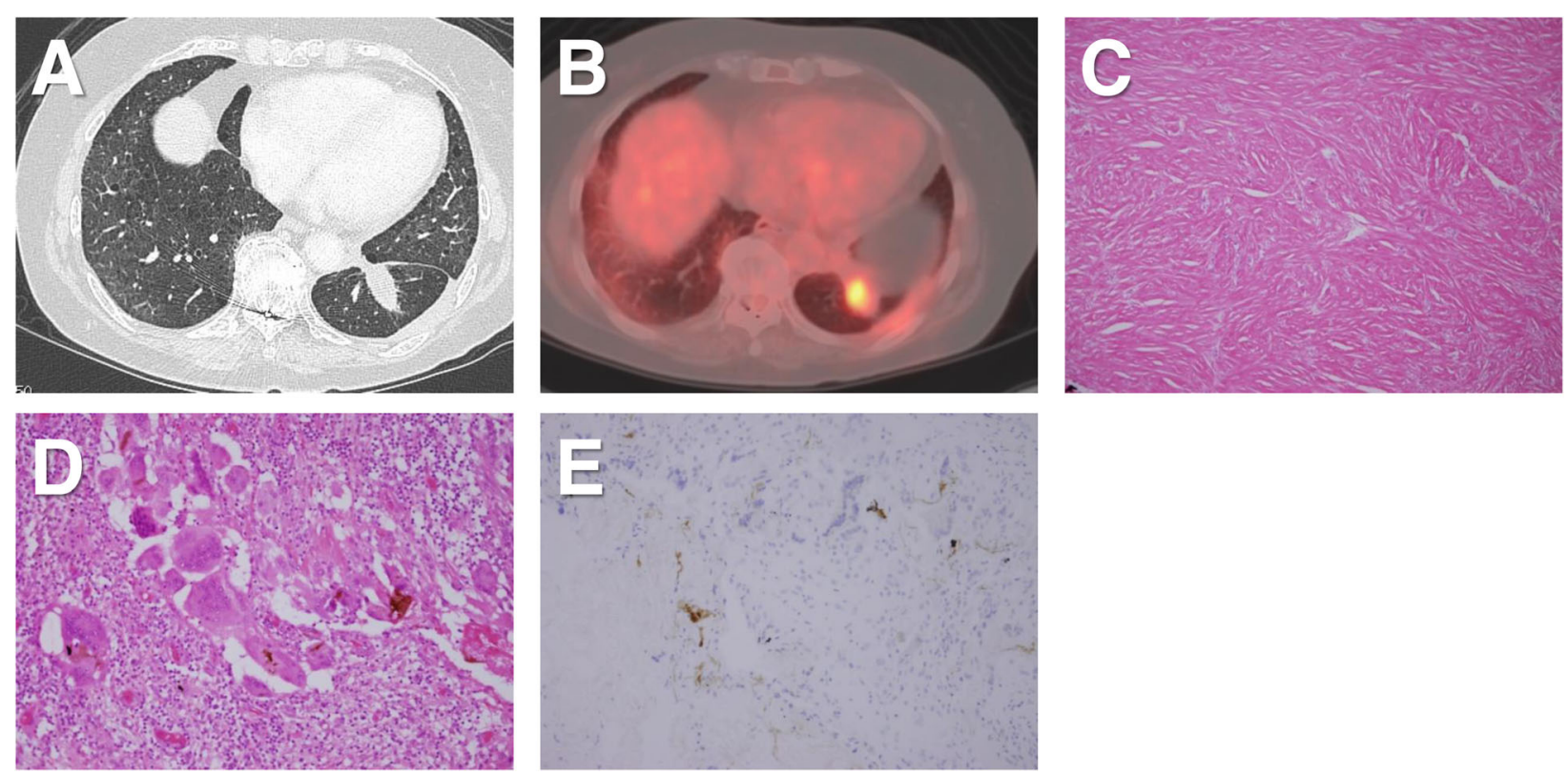

Fig. 1 a Case 1: CT scan shows a nodule measuring $25 \times 22 \mathrm{~mm}$ in the residual left lower lobe. b PET/CT revealed FDG uptake in the nodule (SUVmax: 5.3). c Microscopic view showing hyperplasia of collagen fibers (hematoxylin and eosin staining, original magnification $\times 100$ ). $\mathbf{d}$ Granulomatous nodules with foreign-body giant cells $(\times 400)$. e Immunohistochemistry showing no CEA-positive cells in the granuloma despite CEA-positive alveolar epithelium $(\times 200)$ 

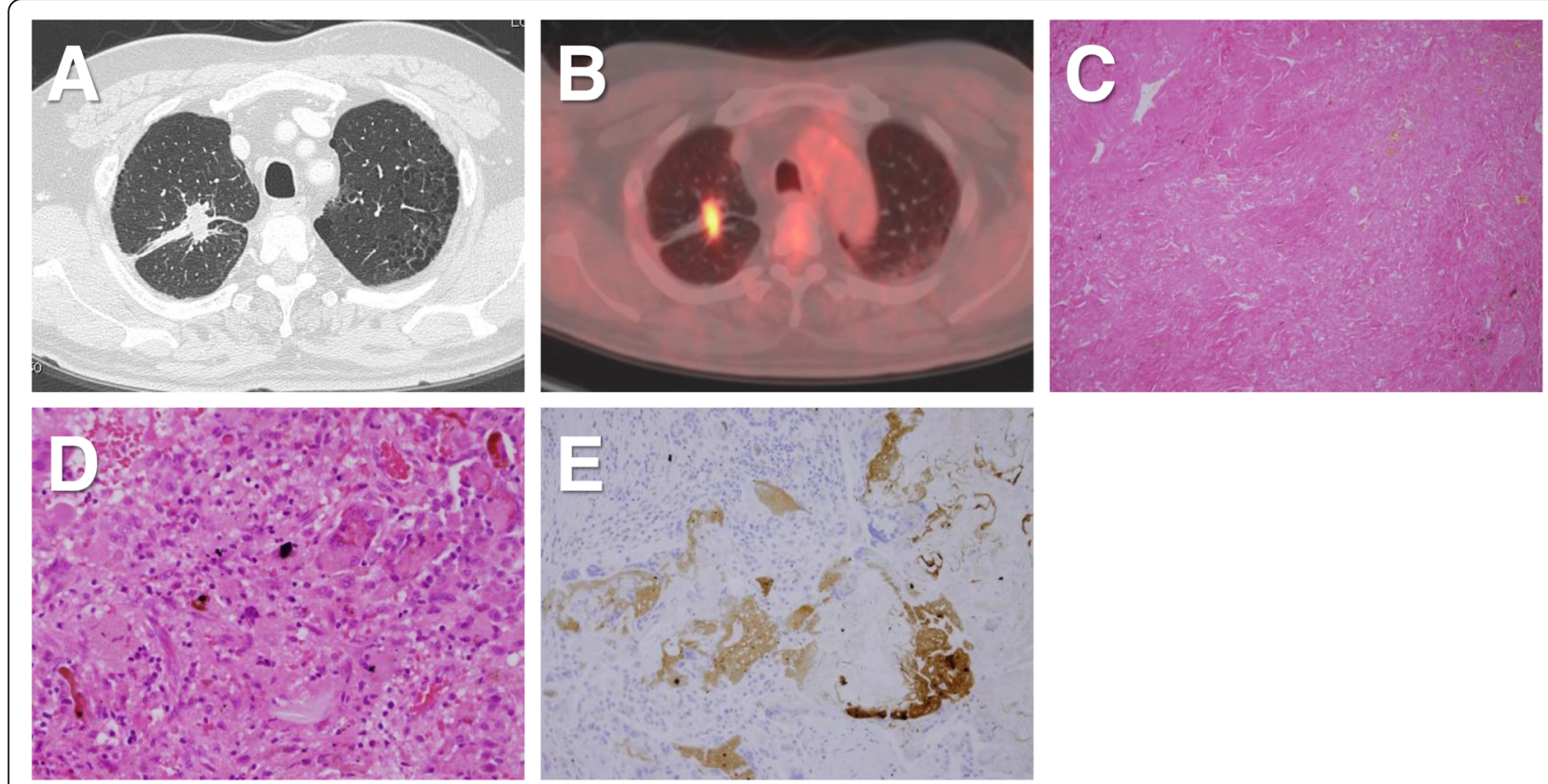

Fig. 2 a Case 2: CT scan shows a nodule in the residual right upper lobe. b PET/CT revealed FDG uptake in the nodule (SUVmax: 6.8). c Microscopic view showing fibrous scars (hematoxylin and eosin staining, original magnification $\times 100$ ). $\mathbf{d}$ Granulomatous nodules with foreignbody giant cells $(\times 400)$. e Immunohistochemistry showing no CEA-positive cells in the granuloma despite CEA-positive secretion ( $\times 200)$

acid; they are useful for preventing air leakage from the lungs [8]. We usually use PGA sheets on the segmental plane cut via electrocautery during pulmonary segmentectomy. Although the mechanism by which granulomas grow is unclear, foreign body reaction may be a main cause of granuloma formation because foreign-body giant cells were observed in the granuloma. The degradation process of PGA occurs in two stages [9]. The first involves the diffusion of water into the amorphous regions of the matrix and simple hydrolytic chain scission of the ester groups. The second stage of degradation largely involves the crystalline areas of the polymer, which become predominant when the majority of the amorphous regions have been eroded. The degradation process takes only a month, but the present cases showed active granulomas at 6 months after the last surgery, suggesting that other mechanisms may have caused granuloma.

In our institution, there were six reoperations against suspected recurrence tumors between 2011 and 2017, and two of them were granulomas presented in this report. Reoperation after lobectomy and segmentectomy is occasionally performed for local recurrence of lung cancer and metastatic lung tumors. Reoperation is usually difficult and involves substantial risk because of severe adhesion surrounding the bronchial stump and pulmonary artery caused by the manipulation during initial surgery. Blood loss in Case 2 was $4100 \mathrm{~mL}$, and the patient required blood transfusion. Therefore, diagnosis of local recurrence of lung malignancy is extremely important, although local recurrence usually occurs in sites difficult to perform bronchoscopic and CT-guided biopsy. PET/ $\mathrm{CT}$ is frequently used as a diagnostic imaging modality in patients with suspected malignancy, but falsepositive findings are quite common [2]. In the present cases, PET/CT revealed FDG uptake in the nodules, but both cases were false-positive findings.

Although serum CEA level measurement is useful for postoperative follow-up of malignant tumors, CEA also may show false-positive results, because the normal mucosal epithelium, such as the oral, colorectal, and bronchial mucosa, secretes CEA. Smoking and aging also result in serum CEA elevation. In the present study, both cases showed serum CEA elevation postoperatively, and CEA levels decreased after reoperation; however, the serum CEA elevation was a false-positive result in both cases. Immunohistochemistry of case 1 showed CEA-positive cells partially in the alveolar epithelium, and CEA-positive cells were observed in the granuloma site of case 2, suggesting that these cells may have elevated serum CEA levels, although it is unclear which cell type secretes CEA.

\section{Conclusions}

We reported two cases of false-positive results on PET/CT scans and serum CEA elevation that mimicked recurrent lung cancer in the intersegmental 
plane after pulmonary segmentectomy. Although this appears to be the first report of granulomas caused by PGA sheets, we should consider the possibility of granulomas by sutures, staplers, and PGA sheets during the postoperative follow-up. Furthermore, recurrence of lung cancer should be diagnosed using pathological findings to avoid unnecessary treatment such as chemotherapy, radiation, and difficult reoperation.

\section{Abbreviations}

CEA: Carcinoembryonic antigen; CT: Computed tomography; FDG PET/

CT: Fluorodeoxyglucose-positron emission tomography / computed

tomography; PGA: Polyglycolic acid; VATS: Video-assisted thoracic surgery

\section{Acknowledgements}

We thank Editage (www.editage.jp) for English language editing.

\section{Authors' contributions}

All authors were involved in perioperative management and surgery. MO and YS conceived the report and wrote the manuscript. All authors have read and approved the final manuscript.

\section{Funding}

This study was no funding supported.

\section{Availability of data and materials}

Not applicable.

\section{Ethics approval and consent to participate}

Ehime University Ethics Committee approved this case report for publication.

\section{Consent for publication}

Written informed consent was obtained from the patients for publication. A copy of the written consent is available for review by the Editor-in-Chief of this journal.

\section{Competing interests}

The authors declare that they have no competing interests.

\section{Author details}

${ }^{1}$ Department of Cardiovascular and Thoracic Surgery, Ehime University Medical School, Toon City, Japan. ${ }^{2}$ Department of Surgery, National Hospital Organization Ehime Medical Center, Toon City, Japan.

Received: 26 September 2019 Accepted: 3 January 2020

Published online: 08 January 2020

\section{References}

1. Keidar Z, Haim N, Guralnik L, et al. PET/CT using 18F-FDG in suspected lung cancer recurrence: diagnostic value and impact on patient management. J Nucl Med. 2004:45:1640-6.

2. Kostakoglu L, Agress H Jr, Goldsmith SJ. Clinical role of FDG PET in evaluation of cancer patients. Radiographics. 2003;23:315-40.

3. Gómez-Román JJ, Sánchez-Velasco P, Ocejo-Vinyals G, Hernández-Nieto E, Leyva-Cobián F, Val-Bernal JF. Human herpesvirus-8 genes are expressed in pulmonary inflammatory myofibroblastic tumor (inflammatory pseudotumor). Am J Surg Pathol. 2001;25:624-9.

4. Tomita M, Matsuzaki Y, Edagawa M, Shimizu T, Hara M, Onitsuka T. Pulmonary granuloma possibly caused by staples after video-assisted thoracoscopic surgery. Ann Thorac Cardiovasc Surg. 2003:9:123-5.

5. Fink $G$, Herskovitz P, Nili M, Hadar H, Rothem A, Spitzer SA. Suture granuloma simulating lung neoplasm occurring after segmentectomy. Thorax. 1993:48:405-6.

6. Yuksel M, Akgul AG, Evman S, Batirel HF. Suture and stapler granulomas: a word of caution. Eur J Cardiothorac Surg. 2007;31:563-5.

7. Munteanu RM, Eva L, DobrovăT BI, et al. Longer survival of a patient with glioblastoma resected with 5-aminolevulinic acid (5-ALA)-guided surgery and foreign body reaction to polyglycolic acid (PGA) suture. Romanian J Morphol Embryol. 2017;58:671-80.

8. Tsuda T, Nakamura T, Yamamoto Y, et al. Prevention of postoperative air leakage from lungs using a purified human collagen membranepolyglycolic acid sheet. Ann Thorac Surg. 1999;68:339-42.

9. Gunatillake PA, Adhikari R. Biodegradable synthetic polymers for tissue engineering. Eur Cell Mater. 2003;5:1-16.

\section{Publisher's Note}

Springer Nature remains neutral with regard to jurisdictional claims in published maps and institutional affiliations.
Ready to submit your research? Choose BMC and benefit from:

- fast, convenient online submission

- thorough peer review by experienced researchers in your field

- rapid publication on acceptance

- support for research data, including large and complex data types

- gold Open Access which fosters wider collaboration and increased citations

- maximum visibility for your research: over $100 \mathrm{M}$ website views per year

At BMC, research is always in progress.

Learn more biomedcentral.com/submissions 